\title{
Biologia e ecologia do arumã, Ischnosiphon polyphyllus (Marantaceae), no arquipélago de Anavilhanas, Rio Negro, Amazônia Central
}

\author{
ERIKA M. NAKAZONO ${ }^{1,3}$ e MARIA TERESA F. PIEDADE ${ }^{2}$
}

(recebido: 5 de setembro de 2002; aceito: 18 de março de 2004)

\begin{abstract}
Biology and ecology of arumã, Ischnosiphon polyphyllus (Marantaceae) on the Anavilhanas archipelago, Rio Negro, Central Amazon). In the islands of the Anavilhanas, the herbaceous species Ischnosiphon polyphyllus, known as "arumã", occupies the understory of flooded black water forest. This plant is utilized by local human populations to produce handcrafts. The aim of the present study is to describe the ecological and biological characteristics of the species, taking into account the criteria of selection of stems used by regional craftsmen. We sampled 153 plots on 27 islands to determine the distribution and abundance of plants along the inundation gradient. In addition, 120 plant tufts distributed on 8 islands were sampled to obtain data on population structure. Higher densities of I. polyphyllus were found in the gradient subject to 2 and $4 \mathrm{~m}$ of inundation. This distribution indicates that the species maximize development in the higher positions in the plains where the abundance of mature stems utilized by the craftsmen is higher. The period of inundation may affect the plant's physiology, morphology, and the reproductive strategies. Vegetative reproduction may play an important role in population survival under conditions of inundation stress. An adequate management of the species is necessary to maintain the species and the local craft activities in a sustainable equilibrium. This is particularly true for the stems removed in the critical position on plains, for example those between 2 and 4 m of flooding.
\end{abstract}

Key words - Amazonia, “arumã”, flooding period, handcraft, management

RESUMO - (Biologia e ecologia do arumã, Ischnosiphon polyphyllus (Marantaceae), no arquipélago de Anavilhanas, Rio Negro, Amazônia Central). Nas ilhas das Anavilhanas a espécie de arumã, Ischnosiphon polyphyllus, ocorre nos sub-bosques das florestas inundáveis de igapós. Esta planta é utilizada por artesãos locais para a confecção de artefatos comercializados. O presente estudo tem como objetivo descrever as características ecológicas e biológicas do arumã, levando-se em consideração critérios de seleção adotados pelos artesãos na extração dos talos. Foram amostradas 153 parcelas em 27 ilhas para realizar a contagem da planta ao longo do gradiente de inundação. Um total de 120 touceiras distribuídas em 8 ilhas foi amostrado para a obtenção de dados estruturais das plantas. A densidade de arumã foi maior no gradiente de 2 a 4 m de profundidade de inundação. Esta distribuição demonstra que, embora a espécie possa tolerar longos períodos alagada, os locais das ilhas nos quais I. polyphyllus atinge seu ótimo de desenvolvimento são aqueles situados nas porções mais elevadas do gradiente, e onde é verificada a maior abundância de talos maduros utilizados pelos ribeirinhos na atividade artesanal. O período de inundação pode estar afetando a fisiologia, a morfologia e as estratégias reprodutivas das plantas, podendo a reprodução assexuada ser uma estratégia de sobrevivência a essa condição de estresse. Para o artesanato local, o manejo da espécie será necessário e especial atenção deverá ser dada à retirada dos talos, principalmente em faixas de relevo com profundidades médias entre 2 e 4 m, de forma a assegurar a manutenção da atividade e da espécie.

Palavras-chave - Amazônia, artesanato, arumã, manejo, período de inundação

\section{Introdução}

Na Amazônia Central o ciclo hidrológico dos grandes rios é previsível e monomodal, o que implica na ocorrência de grandes flutuações de nível da água, cuja amplitude média anual é de $10 \mathrm{~m}$ (Schmidt 1973) e cujos níveis máximos são em geral em junho/julho e os

\footnotetext{
1. Fundação Vitória Amazônica, Rua R/S quadra Q, casa 7, Conjunto Morada do Sol, Aleixo, 69060-080 Manaus, AM, Brasil.

2. INPA/CPBA - Max-Planck, Caixa Postal 478, 69011-970 Manaus, AM, Brasil.

3. Autor para correspondência: arumanzal@yahoo.com.br.
}

mínimos em outubro/novembro (Schmidt 1972). A alternância entre uma fase terrestre e uma fase aquática ao longo do ano leva à inundação periódica das áreas marginais florestadas, pelo transbordamento lateral de águas dos rios ou dos lagos aos quais esses ambientes estão associados (Junk et al. 1989). Essas mudanças recorrentes do ambiente físico promovem modificações químicas e físico-químicas às quais a biota responde por meio de adaptações morfológicas, anatômicas, fisiológicas ou etológicas, ou pela mudança na estrutura da comunidade (Junk 1997).

As florestas inundáveis pelos rios de água branca, com maior fertilidade, são denominadas de várzeas e aquelas associadas aos rios de água claras ou pretas, 
com $\mathrm{pH}$ baixo e pobres em nutrientes, de igapós (Prance 1980). Dentre os igapós de água preta, aqueles ao longo do rio Negro são os mais típicos representantes (Prance 1980). Devido à maior pobreza nutricional dos igapós, a vegetação herbácea de macrófitas aquáticas praticamente inexiste nesses sistemas (Junk \& Piedade 1997), sendo, portanto, de grande importância para as cadeias alimentares aquáticas, principalmente para a ictiofauna, a produção alóctone da floresta alagável.

O Rio Negro, o maior afluente do Rio Amazonas, apresenta, entre outras características peculiares, um dos maiores arquipélagos fluviais do mundo, o Arquipélago das Anavilhanas, constituído de cerca de 400 ilhas. Essas ilhas são alongadas, de formato relativamente triangular, com uma região litoral de deposição de material e uma região de barranco, sistematicamente escavada pelas águas do Rio Negro (Leenheer \& Santos 1980). A substituição de comunidades é claramente evidenciada ao longo da topossequência do gradiente de inundação insular, sendo o número de dias de inundação anual dependente do relevo e idade da ilha (Piedade 1985).

Embora a distribuição diferencial de espécies arbóreas ao longo do gradiente de inundação já tenha sido descrita para o Arquipélago das Anavilhanas (Ferreira 1991, Piedade 1985), o mesmo não foi feito para as espécies herbáceas do sub-bosque. À exceção da citação da presença de alguns grupos de herbáceas mais característicos (Ferreira 1991, Piedade 1985), praticamente inexistem dados, particularmente relacionandos à presença desse grupo de espécies em posições específicas no gradiente de inundação. Entretanto, várias espécies arbustivas ou herbáceas do sub-bosque das florestas de igapó são particularmente importantes para as populações ribeirinhas desses ambientes, uma vez que são utilizadas para a confecção de utensílios caseiros e de roça, tanto para uso doméstico como para comercialização (Nakazono 2000).

Uma das famílias a ser destacada nesse sentido é Marantaceae, cujo gênero Ischnosiphon, popularmente denominado de arumã, é de grande importância, compreendendo cerca de 31 espécies (Anderson 1977), cujas fibras são utilizadas na confecção de diferentes artefatos por caboclos ribeirinhos e diferentes etnias indígenas (Nakazono 2000, FOIRN - ISA 2000). Entretanto, apesar da grande utilização e potencial econômico, praticamente não há informações ecológicas ou de manejo disponíveis para as espécies desse gênero mais utilizadas em atividades artesanais (Nakazono 2000).
No sub-bosque das florestas inundáveis do Rio Negro, particularmente aquelas próximas ao município de Novo Airão (2³7'10" S e 60 57'6" W), uma das espécies de arumã - Ischnosiphon polyphyllus (Poep. \& Endl.) Koern. - era extraída até o final do ano de 2000, com maior intensidade nas ilhas da Estação Ecológica de Anavilhanas. Devido a problemas legais de extração nesta unidade de conservação, passou a ser coletada principalmente em igarapés do entorno daquela cidade. As fibras obtidas do arumã são utilizadas para a confecção de diferentes tipos de artesanato que são comercializados por meio da Associação dos Artesãos de Novo Airão, criada em 1996, com o apoio da Fundação Vitória Amazônica (ONG Conservacionista sediada em Manaus, AM).

O objetivo deste estudo foi descrever as características ecológicas e biológicas do arumã, Ischnosiphon polyphyllus, verificando a sua distribuição ao longo dos gradientes topográficos e de inundação dos igapós das ilhas Anavilhanas, considerando ainda aspectos relacionados aos critérios de seleção das touceiras utilizados pelos artesãos na extração de talos, para fornecer subsídios preliminares para o manejo e conservação da espécie.

\section{Material e métodos}

Área de estudo - O trabalho foi realizado no período de outubro de 1998 a outubro de 1999 nas ilhas do arquipélago da Estação Ecológica de Anavilhanas, localizada no Rio Negro $\left(02^{\circ} 03^{\prime}-03^{\circ} 02^{\prime} \mathrm{Se} 60^{\circ} 22^{\prime}-61^{\circ} 12^{\prime} \mathrm{W}\right)$, cerca de $60 \mathrm{~km}$ ao norte da cidade de Manaus, capital do Estado do Amazonas. O Arquipélago inicia-se aproximadamente $40 \mathrm{~km}$ distante da cidade de Manaus, estendendo-se ao redor de $100 \mathrm{~km}$, rio acima, perfazendo uma área total de 350.000 ha (Ibama 1999).

A pluviosidade anual varia de 1.750 a $2.500 \mathrm{~mm}$, dividindo-se em duas estações durante o ano, uma menos chuvosa entre abril e setembro, chamada de verão, e outra mais chuvosa entre outubro e maio, chamada de inverno. A umidade relativa média anual oscila entre $85 \%$ e $95 \%$. As temperaturas médias anuais também são bastante elevadas na região, ficando entre as isotermas $24^{\circ} \mathrm{C}$ e $26^{\circ} \mathrm{C}$ (Ibama 1999).

O aspecto geral da vegetação das ilhas sofre variação conforme o tamanho das mesmas. As ilhas maiores apresentam, em média, três estratos e as menores apresentam muitas vezes vegetação de porte inferior, podendo ter seu relevo e vegetação totalmente submersos durante as cheias (Piedade 1985). Especialmente nos lagos das ilhas, é comum a presença de extensas faixas de vegetação morta que permanece em pé durante alguns anos, até ser arrastada pelas águas. Essas formações são localmente denominadas de chavascais. Nos sub-bosques dos igapós as famílias mais 
freqüentes são Musaceae, Marantaceae, Zingiberaceae, além da presença predominante de algumas Pteridophyta (Piedade 1985). A fase aquática é compreendida entre os meses de abril e setembro, sendo este último o mês no qual o rio apresenta uma queda brusca no seu nível em relação ao mar (s.n.m.). A média do desnível no mês de setembro nos anos de 1997, 1998 e 1999 foi igual a 5,7 m (dados fornecidos pela Capitania dos Portos de Manaus).

Espécie estudada - O arumã, Ischnosiphon polyphyllus (Poep. \& Endl.) Koern., Marantaceae, é uma erva perene, rizomatosa, caulescente, de tamanho médio a grande, que cresce em locais alagados (Anderson 1977), distribuindo-se desde o alto Rio Orinoco, na bacia do Rio Negro, ao longo do Rio Amazonas, desde Tefé, até a desembocadura desse rio no oceano. A espécie ocorre sob a forma de touceiras, cada uma delas composta por vários caules aéreos, enquanto os caules subterrâneos, rizomatosos, desenvolvem-se a profundidades de 0,10 a $0,50 \mathrm{~m}$, com comprimentos horizontais raramente excedendo valores superiores à faixa entre 0,10 e 0,20 m (Anderson 1977). A partir de duas escavações realizadas em Anavilhanas, foi possível constatar que o rizoma de Ischnosiphon polyphyllus se encontra entre 0,25 e $0,30 \mathrm{~m}$ de profundidade e que a distância entre os rizomas de duas touceiras varia de 0,25 a 0,34 m. A propagação vegetativa ocorre tanto pelos rizomas como por estolões, formados a partir dos caules aéreos. $\mathrm{Na}$ extremidade destes talos, onde se encontra o primeiro nó e de onde são formadas as ramificações de galhos e folhas, também são desenvolvidas raízes adventícias (Begon et al. 1990) que em contato com o solo podem se estabelecer e formar uma nova planta.

Metodologia - Para verificar a distribuição do arumã ao longo do gradiente de inundação das ilhas de Anavilhanas, foram amostradas 153 parcelas de $10 \times 30$ m em 27 ilhas, distribuídas em 38 pontos, distanciados entre si no mínimo $5 \mathrm{~km}$. Essas parcelas foram dispostas uma para cada gradiente de inundação, quando a área apresentou declividade (tabela 1). O gradiente de inundação foi determinado a partir das marcas nas árvores, indicativas da altura máxima que o nível da água atingiu na fase aquática, o que permitiu calcular a profundidade máxima do local e, conseqüentemente, o período de inundação (número de dias/ano) em cada faixa de relevo, nos anos de 1997, 1998 e 1999. O número de dias de inundação ao qual as plantas estão submetidas por faixa de relevo foi rcalculado, determinando a profundidade do ponto de fixação da touceira no relevo, e relacionando essa altura à cota do nível do rio sobre o nível do mar, fornecida pela Capitania dos Portos de Manaus, local mais próximo de coleta desses dados em relação à área de estudo. Como estas cotas são diárias, foi possível calcular o período de inundação para as diferentes touceiras. Com base nas medidas de profundidade e das marcas nas árvores, foram definidos quatro gradientes de inundação: GI1 = 0,00-1,99 m; GI2 = 2,00-3,99 m; GI3 = 4,00-5,99 m; GI4 $=6,00 \geq 8,00 \mathrm{~m}$ (tabela 1 ).

Em cada parcela foi contado o número de touceiras, assim como o número total de talos por touceira, divididos nas seguintes categorias: talos maduros, talos maduros finos, talos jovens e brotos. Essas categorias foram adotadas, tomando como referência o estágio de crescimento dos talos e informações obtidas pelos artesãos e coletores da planta, relacionadas aos critérios de escolha dos talos que são utilizados para a confecção do artesanato. Assim, foi adotada a seguinte definição para a categoria dos talos na touceira: (a) broto - talo novo que ainda não ramificou na extremidade, ou seja, não formou galhos nem folhas, e com altura máxima

Tabela 1. Distribuição das parcelas amostradas nos diferentes gradientes (GI) de altura de inundação (AI), encontrados nos igapós das ilhas de Anavilhanas e seus correspondentes períodos de inundação (PI), dias alagados, em que as touceiras de arumã ficaram submetidas durante a fase aquática dos anos de 1997, 1998 e 1999. GI1 = 0,00-1,99 m; GI2 = 2,00-3,99 m; $\mathrm{GI} 3=4,00-5,99 \mathrm{~m} ; \mathrm{GI} 4=6,00 \geq 8,00 \mathrm{~m}$.

Table 1. Distribution of the plots sampled in different gradients (GI) of height and inundation (AI) found in the igapós of the Anavilhanas Islands, with corresponding periods of inundation (PI), days flooded, and days in which the arumã were underwater during the high-river phase of the years 1997, 1998 and 1999. GI1 = 0,00-1,99 m; GI2 = 2,00-3,99 m; GI3 = 4,00-5,99 m; $\mathrm{GI} 4=6,00 \geq 8,00 \mathrm{~m}$.

\begin{tabular}{|c|c|c|c|c|c|}
\hline $\mathrm{N}^{\circ}$ de parcelas & GI & $\begin{array}{c}\mathrm{AI}(\mathrm{m}) \\
\text { Média (min-max) }\end{array}$ & $\begin{array}{c}\text { PI 1997(dias) } \\
\text { Média (min-max) }\end{array}$ & $\begin{array}{c}\text { PI 1998(dias) } \\
\text { Média (min-max) }\end{array}$ & $\begin{array}{l}\text { PI 1999(dias) } \\
\text { Média (min-max) }\end{array}$ \\
\hline 13 & 1 & $\begin{array}{c}1,6 \\
(1,2-1,9)\end{array}$ & $\begin{array}{c}92,7 \\
(73-105)\end{array}$ & $\begin{array}{c}93,0 \\
(82-100)\end{array}$ & $\begin{array}{c}114,6 \\
(92-145)\end{array}$ \\
\hline 46 & 2 & $\begin{array}{c}2,8 \\
(2,1-4,0)\end{array}$ & $\begin{array}{c}134,6 \\
(111-158)\end{array}$ & $\begin{array}{c}120,7 \\
(102-146)\end{array}$ & $\begin{array}{c}154,7 \\
(126-198)\end{array}$ \\
\hline 54 & 3 & $\begin{array}{c}4,9 \\
(4,0-5,9)\end{array}$ & $\begin{array}{c}173,7 \\
(158-192)\end{array}$ & $\begin{array}{c}169,8 \\
(146-194)\end{array}$ & $\begin{array}{c}203,7 \\
(122-227)\end{array}$ \\
\hline 40 & 4 & $\begin{array}{c}8,8 \\
(6,1-10,0)\end{array}$ & $\begin{array}{c}239,9 \\
(193-254)\end{array}$ & $\begin{array}{c}258,1 \\
(195-281)\end{array}$ & $\begin{array}{c}265,0 \\
(145-296)\end{array}$ \\
\hline
\end{tabular}


igual a 1,0 m; (b) jovem - talo novo, com altura superior a $1,0 \mathrm{~m}$ e com até quatro folhas na extremidade; (c) maduro fino - talo já ramificado na extremidade, com altura superior a 1,0 m e diâmetro altura da base (DAB) menor ou igual a $1,5 \mathrm{~cm}$; (d) maduro - talo já ramificado na extremidade com DAB maior que $1,5 \mathrm{~cm}$; (e) ramo fino - talo já maduro, ramificado na extremidade, com altura menor ou igual a 1,0 m e com DAB menor que $1,5 \mathrm{~cm}$.

Para descrever a estrutura das touceiras quanto à composição dos talos foram amostradas 120 touceiras distribuídas em 8 ilhas mais afastadas de Novo Airão. Essas touceiras foram selecionadas tendo como base o critério de coleta utilizado pelos artesãos, que consiste em procurar as plantas com talos mais adequados para o artesanato, que são os talos maduros e mais grossos.

A distância mínima entre as touceiras amostradas foi de $2 \mathrm{~m}$. Em cada touceira foram medidos diâmetro e altura dos talos da seguinte forma: (a) o DAB foi medido com um paquímetro a $15,0 \mathrm{~cm}$ acima do solo; para brotos com altura menor que 0,50 m essa medida não foi tomada; (b) as alturas dos talos foram medidas somente para talos maduros, jovens, maduros finos e brotos; no caso de já existir ramificação foliar, foi tomada a altura do talo até o primeiro nó da ramificação e a altura total até a ponta extrema da ramificação; (c) os ramos finos foram somente contados.

Mensalmente, no período de 10/1998 a 03/1999, período correspondente à fase terrestre, as touceiras marcadas foram acompanhas para verificar o período de floração (botões e flores abertas). A fenofase floração foi considerada em relação à touceira e não ao número de talos com flores por touceira. O número total de touceiras marcadas foi de 120, entretanto, o número amostral para a determinação da frequiência de touceiras com flor variou de 31 a 120, conforme a inundação as expôs, no inicio da descida das águas, passando a recobri-las após a fase terrestre, quando, no mês de março, apenas 45 touceiras puderam ser visualizadas. Assim, o número total de touceiras observadas variou da seguinte forma em conseqüência da possibilidade de visualização das touceiras não alagadas: outubro, 31; novembro, 120; dezembro, 120; janeiro, 120; fevereiro, 101 e março, 45.

Para comparar as freqüências de touceiras de arumã em diferentes níveis de inundação foi utilizado o teste G. Correlações de Pearson e regressões simples foram realizadas para verificar as relações entre medidas de diâmetro e altura dos talos. As análises foram feitas utilizando o programa de estatística SYSTAT (Wilkinson 1990).

\section{Resultados}

Distribuição do arumã ao longo dos gradientes de inundação (GI) - A variação da densidade de arumã ao longo do gradiente de inundação está apresentada na tabela 2. Devido à diferença no número de parcelas amostradas para cada gradiente de inundação, verificou-se a ocorrência de arumã entre os gradientes através da análise de frequiência das parcelas em relação à densidade encontrada. As diferenças entre as freqüências das touceiras de arumã (presença/ausência) em relação aos diferentes GI foram estatisticamente significativas $(\mathrm{G}=35,366 ; \mathrm{GL}=3 ; \mathrm{p}=0,000)$. A maior presença de touceiras ocorreu no gradiente 2 e a menor, no gradiente 4 , conforme a análise comparativa entre os valores esperados e observados (figura 1).

Estrutura das touceiras de arumã - A tabela 3 apresenta os resultados referentes à estrutura das 120 touceiras amostradas, segundo a categorização dos talos componentes. A regressão linear simples entre diâmetro e altura do talo e altura total do talo foi significativa

Tabela 2. Número médio de touceira, talo maduro, maduro fino, e somatório de jovem e broto, por gradiente de inundação (GI) das ilhas. GI1 = 0,00-1,99 m; GI2 = 2,00-3,99 m; GI3 = 4,00-5,99 m; GI4 = 6,00 28,00 m.

Table 2. Mean number of plants, mature stems, fine stems, and sum of young stems and shoots, by inundation gradient of the islands (GI). GI1 =0,00-1,99 m; GI2 =2,00-3,99 m; GI3 =4,00-5,99 m; GI4 =6,00 $\geq 8,00 \mathrm{~m}$.

\begin{tabular}{|c|c|c|c|c|c|}
\hline GI & $\mathrm{N}^{\mathrm{o}}$ de parcelas & $\begin{array}{l}\text { Touceira } \\
\text { Média } \pm \text { SD } \\
(\min -\max )\end{array}$ & $\begin{array}{l}\text { Talo maduro } \\
\text { Média } \pm \text { SD } \\
(\min -\max )\end{array}$ & $\begin{array}{l}\text { Talo maduro fino } \\
\text { Média } \pm \text { SD } \\
\text { (min-max) }\end{array}$ & $\begin{array}{c}\text { Broto + Talo jovem } \\
\text { Média } \pm \text { SD } \\
\text { (min-max) }\end{array}$ \\
\hline 1 & 13 & $\begin{array}{c}3,4 \pm 7,5 \\
(0-22)\end{array}$ & $\begin{array}{c}4,4 \pm 9,2 \\
(0-31)\end{array}$ & $\begin{array}{c}6,8 \pm 16,3 \\
(0-55)\end{array}$ & $\begin{array}{l}0,46 \pm 1,4 \\
\quad(0-5)\end{array}$ \\
\hline 2 & 46 & $\begin{array}{c}9,4 \pm 16,8 \\
(0-80)\end{array}$ & $\begin{array}{c}14,6 \pm 28,4 \\
(0-120)\end{array}$ & $\begin{array}{c}15,6 \pm 35,4 \\
(0-208)\end{array}$ & $\begin{array}{l}2,3 \pm 5,2 \\
\quad(0-24)\end{array}$ \\
\hline 3 & 54 & $\begin{array}{c}6,4 \pm 16,4 \\
(0-79)\end{array}$ & $\begin{array}{c}3,7 \pm 9 \\
(0-41)\end{array}$ & $\begin{array}{c}14,2 \pm 40,3 \\
(0-213)\end{array}$ & $\begin{array}{c}0,9 \pm 2,9 \\
(0-18)\end{array}$ \\
\hline 4 & 40 & $\begin{array}{c}0,2 \pm 0,9 \\
\quad(0-6)\end{array}$ & $\begin{array}{l}0,4 \pm 2,4 \\
\quad(0-15)\end{array}$ & $\begin{array}{c}0,2 \pm 1 \\
(0-6)\end{array}$ & $\begin{array}{l}0,05 \pm 0,3 \\
\quad(0-2)\end{array}$ \\
\hline
\end{tabular}




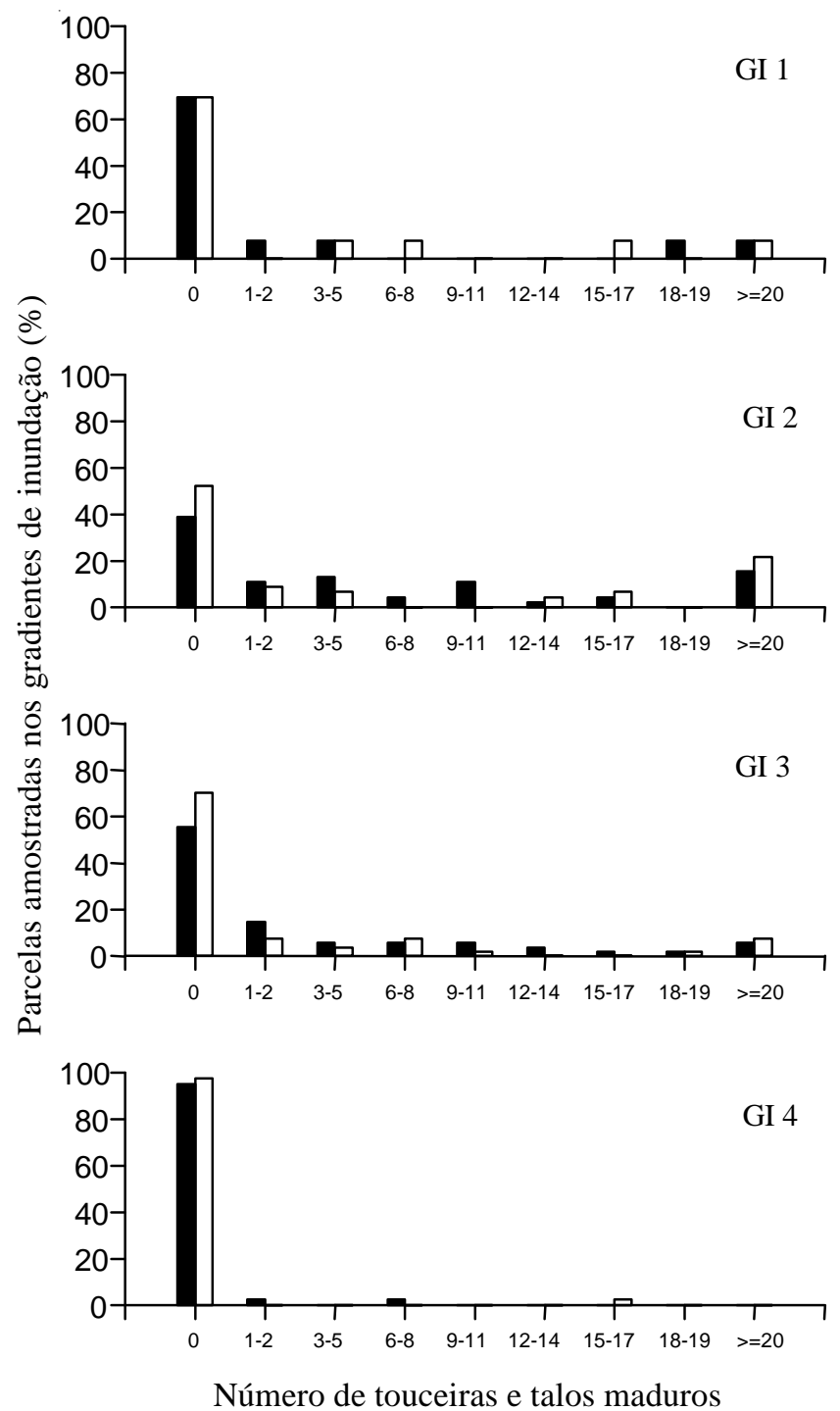

Figura 1. Frequências das parcelas amostradas nos gradientes de altura de inundação dos igapós das ilhas de Anavilhanas (GI1 = 0,00-1,99 m; GI2 = 2,00-3,99 m; GI3 = 4,00-5,99 m; GI4 $=6,00 \geq 8,00 \mathrm{~m}$ ), em relação as classes de número de touceiras e talos maduros ( $\boldsymbol{\square}=$ touceira; $\square=$ talo maduro).

Figure 1. Frequency of the number of plant tufts per plot and mature stems per plot along the gradients of height and inundation of the igapós of the Anavilhanas islands (GI1 = 0,00-1,99 m; GI2 = 2,00-3,99 m; GI3 = 4,00-5,99 m; GI4 = 6,00 $\geq 8,00 \mathrm{~m})(\boldsymbol{\square}=$ plant tuft; $\square=$ mature stem $)$.

$\left(\mathrm{p}=0,001\right.$ e $\mathrm{r}^{2}=0,36 ; \mathrm{p}=0,001$ e $\mathrm{r}^{2}=0,45$, respectivamente). Entretanto, devido ao baixo coeficiente de regressão foi realizada uma análise de correlação simples para averiguar essas relações sem o fator de dependência entre as variáveis. Para ambas as relações entre diâmetro e altura do talo e altura total, as correlações foram positivas, porém não significativas $(\mathrm{p}=0,60$ e $\mathrm{p}=0,65$, respectivamente).
O período de floração do arumã nas ilhas ocorreu de outubro a março, na fase terrestre do ciclo hidrológico. O pico da floração ocorreu logo após o pico da fase terrestre dos igapós da área de estudo, nos meses de novembro e dezembro, do ano de 1998 (figura 2).

\section{Discussão}

Embora ocorrendo ao longo de uma ampla faixa do gradiente de inundação, compreendida entre 2 e $8 \mathrm{~m}$, a maior freqüência de touceiras de Ischnosiphon polyphyllus foi encontrada nas faixas de relevo das ilhas com profundidade de inundação entre 2 e 4 m, o que correspondeu a um tempo médio anual de inundação de 155 dias no ano de 1999. Essa distribuição demonstra que, embora a espécie possa tolerar longos períodos alagada, os locais das ilhas nos quais I. polyphyllus atinge seu ótimo de desenvolvimento são aqueles situados nas porções mais elevadas do gradiente. Corroborando esse fato, também nessas faixas de relevo observou-se maior abundância de talos maduros e maior concentração das touceiras selecionadas para a extração pelos ribeirinhos da região de Novo Airão, para utilização no artesanato.

Apesar da previsibilidade decorrente da repetição do padrão anual do pulso de inundação dos grandes rios amazônicos (Junk et al. 1989), como é o caso do Rio Negro na área de estudo, ciclos plurianuais de secas e cheias mais acentuadas podem ocorrer, influenciando a amplitude da inundação entre anos distintos (Piedade 1985). Esse fator pode explicar a distribuição de Ischnosiphon polyphyllus em uma larga faixa do relevo, correspondente a diferentes profundidades e número de dias de inundação no ano, já que nos gradientes de 4 a $6 \mathrm{~m}$ e 6 a $8 \mathrm{~m}$ de alagação no ano de 1999, o número médio de dias de inundação foi de 204 e 265, respectivamente. Embora essas faixas mais extremas de profundidade pareçam não ser os locais ótimos para o crescimento da planta, já que após estabelecida o comprimento médio alcançado pela planta é de $4 \mathrm{~m}$ de altura, a espécie pode formar extremidades foliares dos talos com comprimentos de até $7 \mathrm{~m}$. Isso poderia explicar sua capacidade de permanecer em profundidades de inundação de até $6 \mathrm{~m}$, mantendo ainda algumas extremidades com folhas em condições não submersas. Por outro lado, mesmo cobertas apenas parcialmente pela água, é possível que elas ainda estejam recebendo luz suficiente para suprir seus gastos energéticos. Medidas de luz nas águas do 
Tabela 3. Estrutura das 120 touceiras amostradas segundo a classificação dos talos.

Table 3. Classification by stem structure of the 120 plants sampled.

\begin{tabular}{|c|c|c|c|c|c|}
\hline Talos da touceira & $\begin{array}{c}\mathrm{N}^{\mathrm{o}} \text { de talos por } \\
\text { touceiras } \\
\text { Média } \pm \mathrm{SD} \\
(\min -\max )\end{array}$ & $\begin{array}{l}\text { Frequência dos } \\
\text { talos }\end{array}$ & $\begin{array}{c}\mathrm{DAB}(\mathrm{cm}) \\
\text { Média } \pm \mathrm{SD} \\
(\min -\mathrm{max}) ; \mathrm{N}\end{array}$ & $\begin{array}{l}\text { Altura talo } \\
\text { Média } \pm \text { SD } \\
\text { (min-max);N }\end{array}$ & $\begin{array}{l}\text { Altura total } \\
\text { Média } \pm \text { SD } \\
(\text { min-max);N }\end{array}$ \\
\hline Broto & $\begin{array}{c}0,5 \pm 1,2 \\
(0-8,0)\end{array}$ & 0,04 & $\begin{array}{c}1,6 \pm 0,32 \\
(1,0-2,3) 13\end{array}$ & $\begin{array}{c}0,54 \pm 0,25 \\
(0,19-0,74) ; 4\end{array}$ & $\begin{array}{c}0,34 \pm 0,23 \\
(0,04-0,93) ; 57\end{array}$ \\
\hline Jovem & $\begin{array}{c}0,4 \pm 0,8 \\
(0-3,0)\end{array}$ & 0,03 & $\begin{array}{c}2,3 \pm 0,62 \\
(0,6-3,9) ; 51\end{array}$ & $\begin{array}{c}2,37 \pm 0,88 \\
(1,0-4,75) ; 41\end{array}$ & $\begin{array}{c}2,85 \pm 1,08 \\
(1,03-5,45) ; 50\end{array}$ \\
\hline Maduro fino & $\begin{array}{c}0,6 \pm 1,1 \\
(0-6,0)\end{array}$ & 0,05 & $\begin{array}{c}1,2 \pm 0,23 \\
(0,6-1,5) ; 72\end{array}$ & $\begin{array}{c}1,57 \pm 0,47 \\
(1,0-3,15) ; 61\end{array}$ & $\begin{array}{c}2,27 \pm 0,63 \\
(1,36-4,0) ; 70\end{array}$ \\
\hline Maduro & $\begin{array}{l}10,3 \pm 7,1 \\
(3,0-36,0)\end{array}$ & 0,84 & $\begin{array}{c}2,5 \pm 0,48 \\
(1,5-4,6) ; 1231\end{array}$ & $\begin{array}{c}2,94 \pm 0,68 \\
(0,97-5,34) ; 1114\end{array}$ & $\begin{array}{c}4,17 \pm 0,93 \\
(1,19-7,27) ; 1207\end{array}$ \\
\hline Ramo fino & $\begin{array}{c}0,5 \pm 2,2 \\
(0-22,0)\end{array}$ & 0,04 & -- & -- & -- \\
\hline
\end{tabular}

Rio Negro e em lagos indicam que até 6-8 $\mathrm{m}$ de profundidade existe um pequeno fluxo de luz (Junk \& Furch 1985). Segundo Junk (1989), é possível que esses baixos fluxos de energia sejam suficientes para manter os pigmentos fotossintéticos intactos.

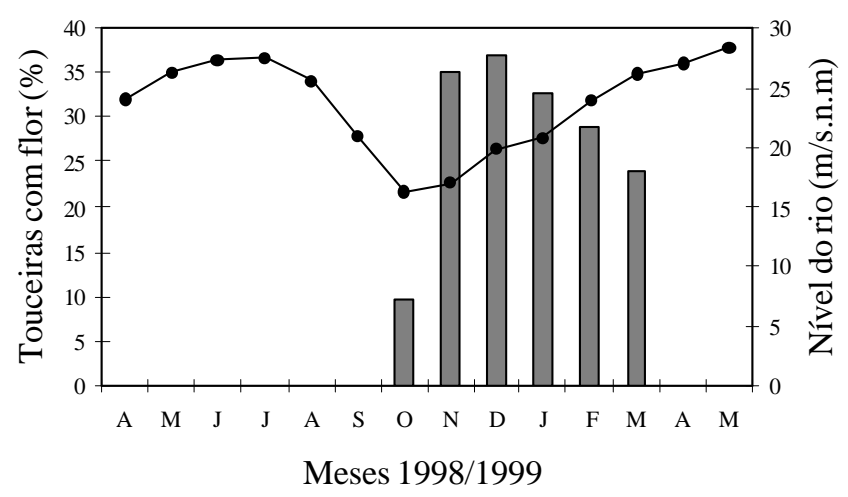

Figura 2. Porcentagens de touceiras de arumã com flor, do total de 120 touceiras amostradas, durante visitas mensais, de outubro de 1998 a março de 1999, nas ilhas de Anavilhanas, em relação à flutuação do nível do rio sobre o mar (n.s.m), no período de 1998 a 1999. Dados fornecidos pela Capitania dos Portos de Manaus ( $\square=$ touceiras com flor; $\longrightarrow \bullet-$ nível do rio).

Figure 2. Relationship between the level of the river above sea level (n.s.m.) and the percentage of 120 "arumã" tufts with flowers during monthly visits to the Anavilhanas Islands between October 1998 and March 1999. Data courtesy of the Manaus Port Authority ( $\square=$ plant tuft with flower; $\longrightarrow \_=$level of the river).
A influência do período de inundação na fisiologia das plantas pode estar afetando a morfologia e as estratégias reprodutivas das mesmas, como parece ser o caso observado nos talos maduros finos. A tendência observada quanto à ocorrência de maiores densidades de talos com menores diâmetros em profundidades de 4 a 6 m de inundação (média de 204 dias alagados no ano de 1999) pode ser uma adaptação das plantas às condições desses ambientes de maior estresse hídrico. Para manter folhas fotossintetizantes acima da superfície da água, as plantas investiriam mais energia para alongar os talos. $\mathrm{O}$ maior comprimento seria, então, obtido às custas de uma redução dos diâmetros. Esse tipo de adaptação já foi verificada para espécies de arroz selvagem da Amazônia (Oryza spp.) por Rubim (1995), em áreas dos Rios Negro e Solimões. Por outro lado, os menores diâmetros podem ser consequiência de um período mais prolongado de inundação ao qual as plantas estão sendo submetidas nessas porções mais profundas (Conserva \& Piedade 2001). Sob tais circunstâncias, condições de redução de oxigênio se estabelecem, o que pode limitar a capacidade fotossintética dessas plantas, levando, portanto, a um menor investimento na produção de biomassa dos caules aéreos, pela redução de seus diâmetros (Rubim 1995). Este aspecto pode ser de grande importância, já que em áreas alagáveis, as condições anaeróbicas decorrentes da inundação prolongada geram déficit de oxigênio, especialmente para os órgãos submersos das plantas, o que leva à redução, entre outras atividades, do crescimento (Junk 1989). 
A reprodução assexuada nessas plantas pode ser outra estratégia de sobrevivência nesses ambientes. Para algumas plantas, a propagação vegetativa pode ser importante no desenvolvimento e uma vantagem em ambientes onde o estabelecimento de plântulas é impedido pela sedimentação ou condições anóxicas do solo (Worbes 1997). A maioria dos arbustos que habita áreas alagadas apresenta propagação vegetativa proveniente de rizomas ou de ramos foliares em contato com o sedimento (Junk \& Piedade 1997). Isso é interpretado como uma forma de compensar as condições adversas às quais principalmente as plântulas dessas espécies são sujeitas para se estabelecerem nesses ambientes (Junk 1989). A plasticidade morfológica de algumas espécies clonais, que possuem a capacidade de dar respostas imediatas a modificações do meio, é considerada como um caráter importante na conquista de ambientes heterogêneos (Dong \& Pierdomicini 1995). I. polyphyllus parece ser um bom exemplo desse tipo de estratégia. A espécie apresenta propagação vegetativa, tanto por rizomas como por estolões gerados a partir dos ramos foliares, além de formar raízes adventícias que, no entanto, ocorrem com menor freqüência nas áreas estudadas (Nakazono 2000).

A maior freqüência de talos maduros, comercialmente utilizados, em locais com profundidades de 2 a $4 \mathrm{~m}$ e menor número de dias de inundação anual (média de 155 dias em 1999) em relação às faixas do relevo com maiores profundidades, parece indicar que nas profundidades menores a planta sofre menor estresse hídrico, podendo investir mais energia no aumento das densidades e diâmetros dos talos. Por meio da propagação vegetativa pelo rizoma, a planta pode estar alocando mais energia na produção de brotos mais vigorosos, aqui caracterizados como maduros, e que crescem com maior rapidez. Isto parece ser confirmado pela comparação entre as densidades dos talos maduros finos, de diâmetro menor, e a densidade dos talos maduros, esta última muito mais baixa nas faixas de relevo entre 4 e $6 \mathrm{~m}$ de inundação, que correspondem à média de 204 dias de alagação anual. Padrão similar foi encontrado para indivíduos de uma população de Paspalum fasciculatum Willd. ex Fluegge (Poaceae), em um lago de várzea da Amazônia central (Conserva $\&$ Piedade 2001).

Se uma utilização mais efetiva da planta vier a ser praticada com fins de intensificação do artesanato de suas fibras, o manejo da mesma será necessário. Dessa forma, especial atenção deverá ser dada à retirada planejada e sustentável dos talos, particularmente daqueles ocorrendo predominantemente nas faixas de relevo com profundidades médias entre 2 e 4 metros, de forma a assegurar a perenização da atividade e da espécie.

Agradecimentos - Agradecemos ao apoio financeiro recebido através do Programa Natureza e Sociedade do WWF-Brasil (World Wildlife Foundation); ao apoio financeiro e logístico da Fundação Vitória Amazônica - Projeto Fibrarte, Instituto Nacional de Pesquisas da Amazônia (INPA) - Ecologia e Conselho Nacional de Pesquisas e Desenvolvimento (CNPq). Ao Instituto Brasileiro do Meio Ambiente e Recursos Naturais Renováveis (Ibama) e Capitania dos Portos de Manaus Sr. Valderino, pelo apoio logístico e técnico. Ao Dr. W.E. Magnusson, no auxílio do delineamento experimental e análise estatística. Aos amigos e biólogos Juan Soler, Olavo Nardy, Manoel Trajano e Jakson Valente, pela ajuda no campo, indispensável para a execução deste trabalho.

\section{Referências bibliográficas}

ANDERSON, L. 1977. The genus Ischnosiphon (Marantaceae). Opera Botanica 43:1-114.

BEGON, M., HARPER, J.L. \& TOWNSENT, C.R. 1990. Ecology, individuals, populations and communities. Blackwell Scientific Publication, Oxford.

CONSERVA, A.S. \& PIEDADE, M.T.F. 2001. Ciclo de vida e ecologia de Paspalum fasciculatum Willd. ex. Fluegge (Poaceae), na várzea da Amazônia Central. Acta Amazonica 31:205-220.

DONG, M. \& PIERDOMINICI, M.G. 1995. Morphology and growth of stolons and rhizomes in three clonal grasses, as affected by different light supply. Vegetatio 116:25-32.

FERREIRA, L.V. 1991. O efeito do periodo de inundação na zonação de comunidades, fenologia e regeneração em uma floresta de igapó na Amazonia Central. Dissertação de mestrado, Instituto Nacional de Pesquisas da Amazônia, Manaus.

FOIRN - ISA. 2000. Arte Baniwa - Cestaria de arumã. Federação das Organizações Indígenas do Rio Negro, Instituto Sócio Ambiental, São Gabriel da Cachoeira.

IBAMA. 1999. Plano de Manejo da Estação Ecológica de Anavilhanas, Instituto do Meio Ambiente, dos Recursos Hídricos e da Amazônia Legal. Instituto Brasileiro do Meio Ambiente e dos Recursos Naturais Renováveis, Brasília.

JUNK, W.J. 1989. Flood tolerance and tree distribution in central Amazonian floodplains. In Tropical forest botanical dynamics - speciation and diversity (L.B. Holm-Nielsen, I.C. Nielsen \& H. Balslev, eds.). Academic Press, London, p.47-64.

JUNK, W.J. 1997. General aspects of floodplain ecology with special reference to Amazonian floodplains. In The central Amazon floodplain (W.J. Junk, ed.). SpringerVerlag, Berlin, p.3-17. 
JUNK, W.J. \& FURCH, K. 1985. The physical and chemical properties of Amazonian waters and their relationships with the biota. In Key Environments Amazonia (G.T. Prance \& T.E. Lovejoy, eds.). Pergamon Press, Oxford, p.3-17.

JUNK, W.J. \& PIEDADE, M.T.F. 1997. Plant life in the floodplain with special reference to herbaceous plants. In The central Amazon floodplain (W.J. Junk, ed.). Springer-Verlag, Berlin, p.147-186.

JUNK, W.J., BAYLEY, P.B. \& SPARKS, R.E. 1989. The flood pulse concept in river-floodplainsystems. In Proceedings of the International Large River Symposium - LARS (D.P. Dodge, ed.). Canadian Special Publication in Fisheries and Aquatic Sciences 106:110-127.

LEENHEER, J.A. \& SANTOS, U.M. 1980. Considerações sobre os processos de sedimentação na água preta ácida do rio Negro (Amazônia Central). Acta Amazonica 10:343-355.

NAKAZONO, E.M. 2000. O Impacto da extração da fibra de arumã (Ischnosiphon polyphyllus, Marantaceae) sobre a população da planta em Anavilhanas, Rio Negro, Amazônia Central. Dissertação de mestrado, Instituto Nacional de Pesquisas da Amazônia, Manaus.
PIEDADE, M.T.F. 1985. Ecologia e biologia reprodutiva de Astrocaryum jauari Mart. (Palmae) como exemplo de população adaptada às áreas inundáveis do rio Negro (igapós). Dissertação de mestrado, Instituto Nacional de Pesquisas da Amazônia, Manaus.

PRANCE, G. 1980. A terminologia dos tipos de florestas Amazônicas sujeitos à inundação. Acta Amazonica 10:495-504.

RUBIM, M.A.L. 1995. Ciclo de vida, biomassa e composição química de duas espécies de arroz silvestre da Amazonia Central. Dissertação de mestrado, Instituto Nacional de Pesquisas da Amazônia, Manaus.

SCHMIDT, G.W. 1972. Seasonal changes in water chemistry of a tropical lake (Lago do Castanho, Amazônia, South America). Verhandlungen der internationalen Vereinnigung für Limnologie 8:613-621.

SCHMIDT, G.W. 1973. Primary production of phytoplankton in the three types of Amazonian waters. II The limnology of a tropical flood-plain lake in central Amazonia (Lago do Castanho). Amazoniana 2:139-203.

WILKINSON 1990. Systat: The system for statistics. Systat Inc., Evnston.

WORBES, M. 1997. The forest ecosystem of the floodplains. In The central Amazon floodplain (W.J. Junk, ed.). Springer-Verlag, Berlin, p.223-260. 